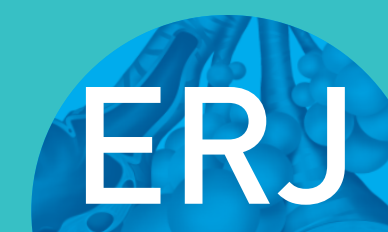

open research
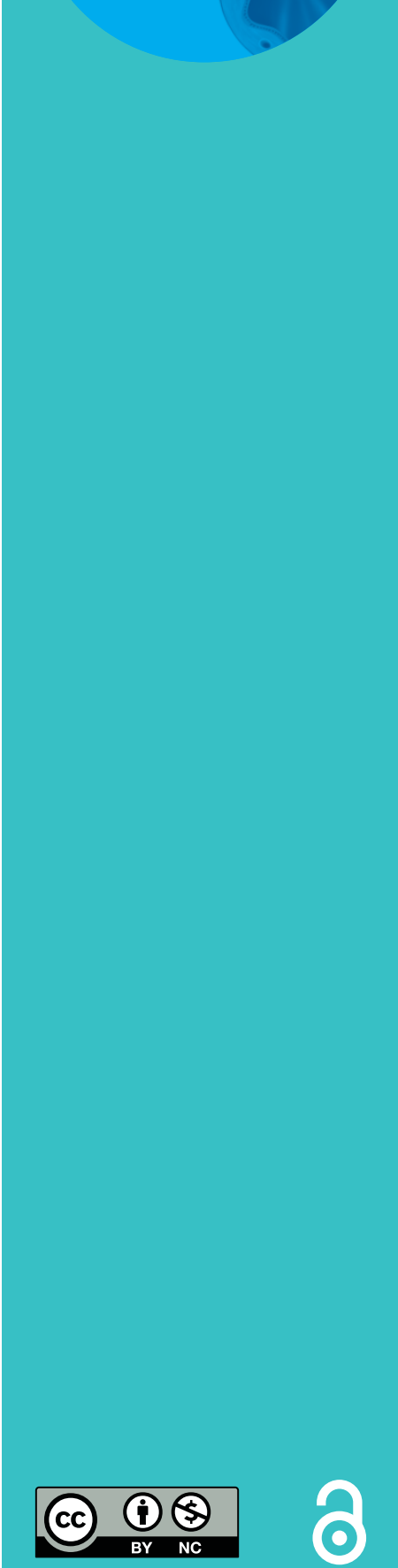

\section{Artificial stone dust-induced functional and inflammatory abnormalities in exposed workers monitored quantitatively by biometrics}

\author{
Noa Ophir ${ }^{1,2}$, Amir Bar Shai ${ }^{1}$, Yifat Alkalay ${ }^{1}$, Shani Israeli ${ }^{1}$, Rafi Korenstein ${ }^{3}$, \\ Mordechai R. Kramer ${ }^{4}$ and Elizabeth Fireman ${ }^{1,2}$
}

Affiliations: 'Laboratory for Pulmonary and Allergic Diseases, Tel Aviv Medical Center, Tel Aviv, Israel. ${ }^{2}$ Environmental and Occupational Medicine, Sackler School of Medicine, Tel Aviv University, Tel Aviv, Israel. ${ }^{3}$ Physiology-Pharmacology Dept, Sackler School of Medicine, Tel Aviv University, Tel Aviv, Israel. ${ }^{4}$ Institute of Pulmonary Diseases, Rabin Medical Center, Tel Aviv University, Tel Aviv, Israel.

Correspondence: Elizabeth Fireman, Laboratory for Pulmonary and Allergic Diseases, Tel Aviv Medical Center, 6 Weizman Street, Tel Aviv 6423906, Israel. E-mail: firemanatlvmc.gov.il

ABSTRACT The manufacture of kitchen and bath countertops in Israel is based mainly on artificial stone that contains $93 \%$ silica as natural quartz, and $~ 3500$ workers are involved in cutting and processing it. Artificial stone produces high concentrations of silica dust. Exposure to crystalline silica may cause silicosis, an irreversible lung disease. Our aim was to screen exposed workers by quantitative biometric monitoring of functional and inflammatory parameters.

68 exposed artificial stone workers were compared to 48 nonexposed individuals (controls). Exposed workers filled in questionnaires, and all participants underwent pulmonary function tests and induced sputum analyses. Silica was quantitated by a Niton XL3 X-ray fluorescence spectrometer.

Pulmonary function test results of exposed workers were significantly lower and induced sputa showed significantly higher neutrophilic inflammation compared to controls; both processes were slowed down by the use of protective measures in the workplace. Particle size distribution in induced sputum samples of exposed workers was similar to that of artificial stone dust, which contained aluminium, zirconium and titanium in addition to silica.

In conclusion, the quantitation of biometric parameters is useful for monitoring workers exposed to artificial stone in order to avoid deterioration over time.

@ERSpublications

Novel biomarkers in induced sputum can detect and monitor lung injury from artificial dustinduced silicosis http://ow.ly/YriTo

\section{Received: Nov 102015 | Accepted after revision: Feb 052016}

Support statement: The work was supported by The Committee for Research and Prevention in Occupational Safety and Health Israel. Funding information for this article has been deposited with FundRef.

Conflict of interest: None declared

Copyright $\odot$ ERS 2016. This article is open access and distributed under the terms of the Creative Commons Attribution Non-Commercial Licence 4.0 


\section{Introduction}

Silicosis is a fibrotic lung disease initiated by prolonged and extensive exposure to respirable free crystalline silica. Occupations traditionally associated with increased risk of silicosis include glass and pottery making, mining and quarrying, sandblasting, and any construction trades that generate silica dust through stone or concrete work. A high prevalence of advanced, life-threatening silicosis linked to extensive use of artificial stone with high silica content in the marble industry was reported in Israel [1]. Similar outbreaks of occupational silicosis have been reported in Spain, Italy and, more recently, in Australia and the USA [2-6]. The artificial stone is a composite material made of quartz as the major filler, with the addition of coloured glass, shells, metals or mirrors bound together by a polymer resin. Environmental exposure metrics defined the permissible exposure limits for respirable silica as varying between 0.025 and $0.35 \mathrm{mg} \cdot \mathrm{m}^{-3}$ [7], but these standards have not been confirmed as being fully protective by epidemiology studies. Environmental monitoring is carried out by measuring the number of toxic particles in the air of a given location. As such, it ignores the pollutant's internal dose (body burden) at the personal level, the route of exposure (e.g. inhalation) and the markers of early adverse health effects (e.g. inflammatory responses). The effect of particle deposition in the lungs and its toxicity by means of the inflammatory effect calls for biometric monitoring in order to determine its impact on human health. An easily performed, noninvasive biological monitoring system would be of enormous value for the early detection of pulmonary injury and the screening of large populations of individuals exposed to noxious particulate matter in the work environment.

Induced sputum is a noninvasive method that has demonstrated the heterogeneity of airway inflammation in asthma, chronic obstructive pulmonary disease (COPD) and chronic cough [8]. In addition, several occupational and environmental studies have shown that quantitative and qualitative analysis of particles recovered by induced sputum can serve as a biological monitoring method in addition to the traditional sources of exposure history and environmental measurements [9-12].

The current gold standard for diagnosing silicosis is by chest radiography and pulmonary function tests (PFTs) [13]. Lung biopsies can also be used. However, a review that explored the relationship between PFTs and silicosis indicated that reduced lung function was more likely to be associated with higher International Labor Office radiographic categories of silicosis of the than with lower ones. No consistent pattern of association was observed with the latter, suggesting that PFTs are not sensitive enough to detect early lung injury among exposed populations [14].

We studied a population of individuals employed in the manufacture of kitchen and bathroom countertops made of an artificial raw material containing $>90 \%$ free crystalline silica. In Israel, according to the Israeli Institute for Occupational Safety and Hygiene, the maximum exposure rate to $\mathrm{SiO}_{2}$ dust is $0.1 \mathrm{mg} \cdot \mathrm{m}^{-3}$ for respirable dust $(\leqslant 7 \mu \mathrm{m})$ and $0.3 \mathrm{mg} \cdot \mathrm{m}^{-3}$ for floating dust. Importantly, these standards refer to environmental exposure and ignore cumulative internal exposure.

We investigated here novel particulate deposition in airways and inflammatory biomarkers (i.e. particle size distribution and percentage of neutrophils in induced sputum samples) retrieved by noninvasive procedures to screen a large population of workers exposed to artificial stone. Our aim was to apply sensitive biological markers for the early identification of workers at high risk of developing advanced stages of silicosis.

\section{Methods}

Study design and study population

116 individuals working mainly with artificial stone dust up to the last 20 years were recruited from small enterprises throughout the country. Recruitment was by physician referral, direct contact with marble factories and self-referral. Over one-third (36.8\%) of the exposed workers had no previous diagnosis of silicosis and $63.2 \%$ were known to have silicosis on the day of evaluation. Ethical approval was granted by the Institutional Ethics Committee in Tel Aviv Sourasky Medical Center. All participants gave written informed consent, and paid one visit for clinical assessment by PFT and sputum induction. The controls were healthy, nonexposed individuals from the community who volunteered to undergo PFTs and sputum induction.

\section{Occupational questionnaire and exposure assessment}

A self-reported occupational questionnaire was completed by all exposed workers. The questionnaire was validated by the Epidemiological and Preventive Medicine Dept in the Tel Aviv University School of Public Health. It included demographic and occupational parameters, smoking and alcohol habits, a general health profile, respiratory protective measures applied in the workshop (water cutting machine and dust ventilation system), and personal protective equipment (mask, goggles, gloves, special footwear and cloths).

\section{Pulmonary function tests}

PFTs were performed using a Masterlab spirometer (Masterlab E; Jaeger, Wurzburg, Germany). Measurements were carried out according to standard protocols of the American Thoracic Society guidelines [15]. 


\section{Sputum induction and processing}

Sputum induction and processing were performed with an aerosol of hypertonic saline generated by an Ultrasonic Nebulizer, model Omron U1 (Omron Health Care, Lake Forest, IL, USA), that has an output of $0.5 \mathrm{~mL} \cdot \mathrm{min}^{-1}$ and particles with $<5 \mu \mathrm{m}$ aerodynamic mass median diameters $[16,17]$.

\section{Particle analyses: size and shape}

Particle size analyses were performed according to a laser technique based on the time of transition theory using a DIPA 2000 Analyzer (Donner Technologies Ltd, Israel) [18, 19]. The experiment was repeated three times in three different tubes (a total of nine measurements). The particle measurement was performed long enough to reach $95 \%$ confidence intervals. The results of the particle size distribution were the average of three sequential measurements. The results were expressed as cumulative values for each fraction of particles.

The curve of the particulate matter retrieved from induced sputum samples that represented the raw material (i.e. the artificial stone collected from one of the factories) to which the stone workers were exposed was superimposed over the curve of the artificial stone dust analysis.

\section{Quantification of mineral content using an X-ray fluorescence spectrometer analyser}

Induced sputum samples were obtained from three exposed workers randomly chosen from high-quality sputum specimens and three nonexposed individuals from the control group. After separation of the plugs and viscous materials, all fractions of induced sputum were preserved in $10 \%$ formalin and stored at $4^{\circ} \mathrm{C}$ until analysis of mineral particles. We used the samples containing both extracellular and intracellular particles for the X-ray fluorescence (XRF) analysis. The samples were treated with $14 \%$ formamide solution and filtered onto a $0.8-\mu \mathrm{m}$ carbon-coated Nuclepore filter (Millipore Filter Corp., Bedford, MA, USA). Each filter was scanned twice in different areas by a Niton XL3 XRF analyser (Thermo Fischer Scientific, Munich, Germany) and the average of two repeated measurements of three subjects for each group was calculated. Artificial and natural stone dust samples were obtained at two plants, each involved exclusively in one type of stone work.

\section{Statistical analysis}

Comparisons between groups were performed by an independent t-test, the Kruskal-Wallis test and the Chi-square test. Correlation between particles $<5 \mu \mathrm{m}$ and continuous variables was assessed by Spearman correlation. The percentages of particles $\leqslant 5$ and $\leqslant 10 \mu \mathrm{m}$ were divided into dichotomy parameters by a receiver operating characteristic (ROC) curve at the point with the highest sensitivity and specificity that differentiates between subjects with or without neutrophilic inflammation. Associations between the use of protective methods (yes or no) and various covariates were tested by the Fisher exact test for categorical variables. All statistical analyses were performed using the SPSS software version 22.0 for Windows (SPSS, Chicago, IL, USA). All p-values are two-sided and a p-value $<0.05$ was considered significant.

\section{Results}

The study population included 116 males (68 artificial stone-exposed workers and 48 individuals with no occupational exposure history). 32 were past smokers and none was a current smoker. The exposed workers were older (mean \pm SD $48.6 \pm 11.4$ versus $38.0 \pm 17.1$ years, $\mathrm{p}<0.01$ ) and had a higher body mass index (27.0 \pm 4.0 versus $23.7 \pm 2.8$ ) than the nonexposed controls (table 1 ).

The PFT scores of the exposed workers were significantly lower than those of the controls (table 2). The exposed workers had a higher percentage of neutrophils in their induced sputum samples $(68.6 \pm 22.6 \%$ versus $46.7 \pm 18.8 \%$, respectively; $\mathrm{p}<0.001$ ), and a lower percentage of macrophages and eosinophils ( $16.8 \pm 18.9 \%$ versus $30.4 \pm 23.1 \%$ and $1.3 \pm 3.0 \%$ versus $8.5 \pm 3.6 \%$, respectively; $p<0.001$ ) (table 2 ).

\section{TABLE 1 Demographic and clinical parameters of the study population $(n=116)$}

\begin{tabular}{lcccc} 
& Males/females & Age years & Exposure years & Body mass index \\
\hline Exposed workers & $68 / 0$ & $48.3 \pm 11.1$ & $20.5 \pm 10.0$ & $27.0 \pm 4.0$ \\
Nonexposed controls & $32 / 16$ & $38.0 \pm 17.1$ & 0 & $23.7 \pm 2.8$ \\
p-value* & $<0.01$ & $<0.01$ & & $<0.01$
\end{tabular}

Data are presented as mean \pm SD unless otherwise stated. *: $p<0.05$ for age and body mass index (t-test) and sex (Pearson Chi-squared test). 
TABLE 2 Pulmonary function tests and differential cells counts in induced sputum

\begin{tabular}{|c|c|c|c|}
\hline & Exposed workers & Nonexposed controls & p-value* \\
\hline VC \% pred & $77.4 \pm 18.6(n=68)$ & $97.8 \pm 14.1(n=35)$ & $<0.01$ \\
\hline TLC \% pred & $93.9 \pm 15.4(n=68)$ & $106.5 \pm 10.7(n=35)$ & $<0.01$ \\
\hline FVC $\%$ pred & $79.0 \pm 19.8(n=68)$ & $98.3 \pm 13.7(n=44)$ & $<0.01$ \\
\hline FEV $1 \%$ pred & $74.6 \pm 22.5(n=68)$ & $97.9 \pm 14.4(n=45)$ & $<0.01$ \\
\hline FEV 1 /FVC & $76.0 \pm 12.1(n=68)$ & $85.5 \pm 8.9(n=45)$ & $<0.01$ \\
\hline$D \mathrm{LCO}_{\mathrm{sb}} \%$ pred & $75.8 \pm 17.6(n=66)$ & $91.4 \pm 11.0(n=36)$ & $<0.01$ \\
\hline Neutrophils \% & $68.6 \pm 22.6(n=59)$ & $46.7 \pm 18.8(n=41)$ & $<0.01$ \\
\hline Macrophages \% & $16.8 \pm 18.9(n=59)$ & $30.4 \pm 23.1(n=42)$ & $<0.01$ \\
\hline Eosinophils \% & $1.3 \pm 3.0(n=59)$ & $8.5 \pm 13.6(n=42)$ & $<0.01$ \\
\hline Lymphocytes \% & $12.5 \pm 9.1(n=59)$ & $12.8 \pm 6.9(n=42)$ & 0.859 \\
\hline
\end{tabular}

By superimposing the curves of the particle size distribution of raw material and the induced sputum samples, we demonstrated that they both had a similar distribution pattern. The particles derived from the exposed group's samples contained a significantly higher fraction of small particles $(<5 \mu \mathrm{m})$ and a lower percentage of particles between 5 and $10 \mu \mathrm{m}$ than the control group $(94.0 \pm 5.6 \%$ versus $89.4 \pm 4.7 \%(\mathrm{p}<0.01)$ and $4.3 \pm 3.7 \%$ versus $6.2 \pm 4.6 \%$ ( $\mathrm{p}=0.025$ ), respectively) (tables 3 and 4 , and figure 1 ).

The use of dust protection measures (masks, water cutting machines, ventilation and cloths) decreased the percentage of accumulated particles in the airways for all sizes tested $(61.6 \pm 11.8 \%$ versus $69.80 \pm 10.7 \%$, $92.2 \pm 5.0 \%$ versus $95.5 \pm 5.8 \%$ and $97.8 \pm 1.5 \%$ versus $98.7 \pm 2.5 \%$ for $<2 \mu \mathrm{m},<5 \mu \mathrm{m}$ and $<10 \mu \mathrm{m}$ in protected versus unprotected workers, respectively $(\mathrm{p}<0.01)$ ) (table 3 ). The particles retrieved from induced sputa of the exposed group were significantly smaller, less spherical and less smooth, more concave and more opaque than those retrieved from the unexposed group (table 4). Moreover, they were significantly changed by the use of personal protective precautions.

We performed a quantitative analysis using the XRF instrument of the particles retrieved from the induced sputa of three exposed workers and three nonexposed controls, all randomly chosen, and compared the results to the raw artificial and the natural stone dust. The analysis showed that both the artificial stone and the induced sputum samples of exposed workers contained significantly higher concentrations of silica (5739.6 ppb versus below the limit of detection in induced sputum and 647603.4 versus $4041.9 \mathrm{ppb}$ in the raw material). Other metals were also identified (table 5).

The accumulation of particles $<5 \mu \mathrm{m}$ negatively correlated with single-breath diffusing capacity of the lung for carbon monoxide $\left(D_{\mathrm{LCO}} \mathrm{sb}\right)$, forced expiratory volume in $1 \mathrm{~s}$ and forced vital capacity (FVC), and positively correlated with neutrophil counts in the induced sputum specimens (figure 2).

Having demonstrated that neutrophils in the induced sputa of exposed workers were significantly more numerous than those from the controls and that their percentage was positively correlated with particle

TABLE 3 Comparison of size of particulate matter in the study population according to use of personal protective precautions

\begin{tabular}{|c|c|c|c|c|c|c|}
\hline \multirow{2}{*}{$\begin{array}{l}\text { Particle } \\
\text { size } \mu \mathrm{m}\end{array}$} & \multirow{2}{*}{$\begin{array}{c}\text { Exposed } \\
\text { workers }(n=58)\end{array}$} & \multirow{2}{*}{$\begin{array}{c}\text { Nonexposed } \\
\text { controls }(n=44)\end{array}$} & \multirow[t]{2}{*}{ p-value } & \multicolumn{3}{|c|}{ Protection* } \\
\hline & & & & Yes $(n=27)$ & No $(n=30)$ & p-value \\
\hline$<2$ & $66.0 \pm 11.8$ & $58.0 \pm 21.5$ & $<0.01$ & $61.6 \pm 11.8$ & $69.80 \pm 10.7$ & 0.01 \\
\hline$<5$ & $94.0 \pm 5.6$ & $89.4 \pm 4.7$ & $<0.01$ & $92.2 \pm 5.0$ & $95.5 \pm 5.8$ & $<0.01$ \\
\hline$<10$ & $98.3 \pm 2.1$ & $95.4 \pm 4.3$ & $<0.01$ & $97.8 \pm 1.5$ & $98.7 \pm 2.5$ & $<0.01$ \\
\hline $5-10$ & $4.3 \pm 3.7$ & $6.2 \pm 4.6$ & 0.025 & $5.6 \pm 3.7$ & $3.2 \pm 3.4$ & 0.013 \\
\hline
\end{tabular}

Data are presented as mean \pm SD $\%$ unless otherwise stated. Protective measures applied in the workshop and personal protective equipment are described in the Methods section. Sizes measured by image analysis as described in the Methods section. The use of protection means was evaluated by the questionnaire. *: $p<0.05$ (t-test) for dust exposure and Kruskal-Wallis for protection method. 
TABLE 4 Comparison of shape of particulate matter in the study population according to use of personal protective precautions

\begin{tabular}{|c|c|c|c|c|c|}
\hline & \multirow{2}{*}{$\begin{array}{c}\text { Exposed } \\
\text { workers }(n=29)\end{array}$} & \multirow{2}{*}{$\begin{array}{l}\text { Nonexposed } \\
\text { controls }(n=40)\end{array}$} & \multicolumn{3}{|c|}{ Protection* } \\
\hline & & & Yes (n=13) & No $(n=16)$ & p-value \\
\hline Grey level & $85.0 \pm 1.0$ & $114.8 \pm 29.9$ & $85.3 \pm 1.0$ & $84.8 \pm 1.0$ & 0.254 \\
\hline Average Ferret diameter $\mu \mathrm{m}$ & $3.6 \pm 0.7$ & $4.4 \pm 1.7$ & $3.15 \pm 0.32$ & $3.90 \pm 0.84$ & 0.014 \\
\hline Circularity & $0.46 \pm 0.02$ & $0.53 \pm 0.1$ & $0.47 \pm 0.02$ & $0.45 \pm 0.01$ & 0.084 \\
\hline Convexity & $0.85 \pm 0.009$ & $0.87 \pm 0.03$ & $0.853 \pm 0.01$ & $0.847 \pm 0.008$ & 0.066 \\
\hline Concavity & $0.84 \pm 0.006$ & $0.86 \pm 0.03$ & $0.841 \pm 0.006$ & $0.836 \pm 0.005$ & 0.031 \\
\hline
\end{tabular}

Data are presented as mean \pm SD unless otherwise stated. Protective measures applied in the workshop and personal protective equipment are described in the Methods section. Sizes measured by image analysis as described in the Methods section. The use of protection means was evaluated by the questionnaire. *: $p<0.05$ (t-test) for dust exposure and Kruskal-Wallis for protection method.

accumulation results, we analysed which threshold of accumulated particles had the best specificity and sensitivity to predict neutrophilic inflammation $(>65 \%)$. The ROC curve showed a sensitivity of $60 \%$ and a specificity of $63 \%$ for the accumulation of $91.93 \%$ particles $<5 \mu \mathrm{m}$, and a sensitivity of $88 \%$ and a specificity of $38 \%$ for the accumulation of $95.17 \%$ particles $<10 \mu \mathrm{m}$. These thresholds represented a significant difference in neutrophil counts among the two groups, with a trend towards neutrophilic inflammation for the group with more particles $<5 \mu \mathrm{m}$ and $<10 \mu \mathrm{m}$ in induced sputum $(64.4 \pm 24.9 \%$ and $65.7 \pm 25.2 \%$, respectively; $\mathrm{p}<0.05$ ) (table 6).

Notably, the unprotected workers also had an increased risk of having more particles $<5 \mu \mathrm{m}$ and $<10 \mu \mathrm{m}$ in induced sputum samples, as well as neutrophilic inflammation and $D \mathrm{LCO}_{\mathrm{sb}}$ impairment, compared to the protected group (table 7). The accumulated amounts of particles and neutrophils in induced sputum samples over time was higher in the exposed workers who reported not having used any kind of protection compared to those who did so regularly. Their $D \mathrm{LCO}_{\mathrm{sb}}$ also declined more rapidly (Chi-squared test $\mathrm{r}=3.976, \mathrm{p}=0.046$ ) (figure 3).

\section{Discussion}

The diagnosis of silicosis is traditionally based on clinical history and imaging findings [7, 13, 20]. Although they are not used as diagnostic tools, PFTs are widely employed in the assessment of individuals with silicosis in order to evaluate functional parameters of the lung [21]. However, none of these methods is sensitive enough to detect changes at an early stage that might point to the onset of tissue damage. We had previously shown that abnormal radiological findings of lung pathology were present without any comparable evidence in functional parameters in a group of dental technicians [12]. Similar findings were

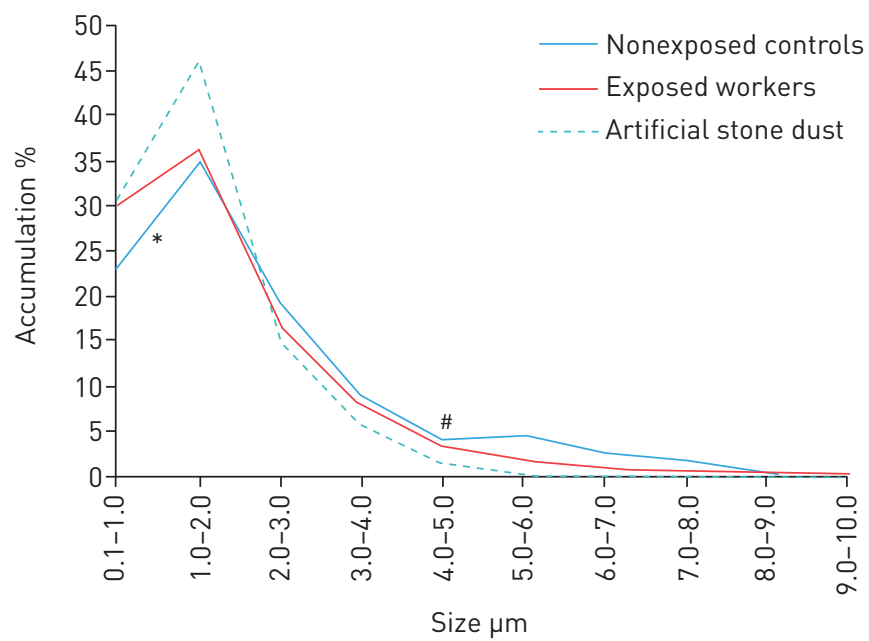

FIGURE 1 Accumulation of particulate matter in induced sputum in the exposed and nonexposed (control) workers, and in the raw material. Particle size was assessed by a DIPA analyser, as described in the Methods section. *: $p<0.05$ (independent t-test) for accumulated particles $5-6 \mu \mathrm{m}$; \#: $p<0.05$ (independent $t-t e s t$ ) for accumulated particles 0.1-1 $\mu \mathrm{m}$. 


\begin{tabular}{|c|c|c|c|c|c|}
\hline & Nonexposed controls & Exposed workers & p-value & Natural stone & Artificial stone \\
\hline Zinc & $<L O D$ & $160.2 \pm 97.8$ & $<0.01$ & $<L O D$ & $1233.7 \pm 24.78$ \\
\hline Copper & $178.4 \pm 16.6$ & $216.8 \pm 58.1$ & 0.217 & $<L O D$ & $57.8 \pm 13.92$ \\
\hline Iron & $293.4 \pm 59.6$ & $1479.2 \pm 760.1$ & 0.012 & 507.260 .34 & $3574.0 \pm 80.8$ \\
\hline Titanium & $<$ LOD & $603.6 \pm 268$ & 0.064 & $<L O D$ & $41412.2 \pm 255.7$ \\
\hline Calcium & $4522 \pm 811.2$ & $19321.2 \pm 10151$ & 0.016 & $546368.6 \pm 309$ & $9058.2 \pm 245.9$ \\
\hline Aluminium & $<L O D$ & $3192.7 \pm 2052$ & $<0.01$ & $899.1 \pm 170.3$ & $20146.9 \pm 430.2$ \\
\hline Silica & $<L O D$ & $5739.6 \pm 1577$ & $<0.01$ & $4041.9 \pm 102$ & $647603.4 \pm 1198$ \\
\hline Chloride & $517548.7 \pm 136374$ & $18634.9 \pm 7005$ & $<0.01$ & $<L O D$ & $13167.5 \pm 96.7$ \\
\hline Sulfur & $153316.3 \pm 57024$ & $434674.1 \pm 213233$ & 0.022 & $794.8 \pm 41.7$ & $3350.4 \pm 89.7$ \\
\hline
\end{tabular}

Data are presented as the mean \pm SD of two measurements in three subjects for each group. LOD: limit of detection. $p<0.05$ (independent t-test).

reported in 105 dental technicians in Paris, France, whose PFT values (normal) did not correlate to the duration of exposure [21], and in silicotic stonemasons in Brazil who had lower (but normal) values of FVC and total lung capacity compared to co-workers without evidence of silicosis [22]. Consistent with those results, we currently found lower PFT parameters among the exposed workers compared to controls but within normal ranges for all tested parameters except $D \mathrm{LCO}_{\mathrm{sb}}$.

These functional parameters are clearly not sensitive enough to alert to impending lung injury. We demonstrate here what we believe to be novel biomarkers capable of identifying populations at high risk of advanced inflammatory and functional deterioration as the result of continuing exposure to artificial stone dust. Induced sputum samples in exposed workers showed neutrophilic inflammation compared to nonexposed controls. The biomarkers also provided evidence of the benefit of personal protection in potentially hazardous workplaces.

Our findings are in accordance with those from previous studies performed in our laboratory in which the neutrophil counts in induced sputa were shown to correlate to exposure duration and disease severity in welders [9], dental technicians [12] and firefighters that were on duty during the World Trade Center
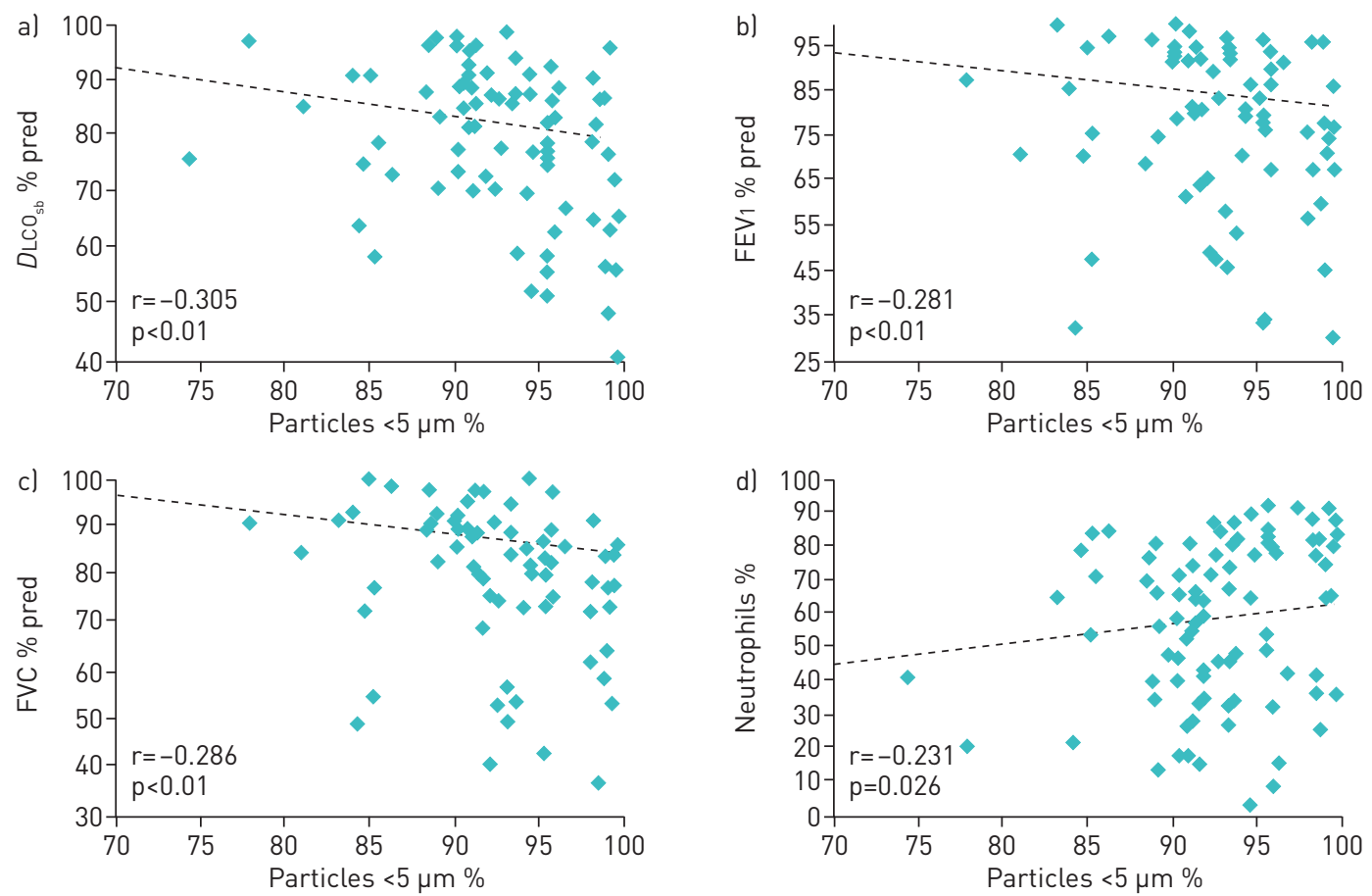

FIGURE 2 Correlation between particles in induced sputum $<5 \mu \mathrm{m}$ and al single-breath diffusing capacity of the lung for carbon monoxide $\left.\left(\mathrm{DLCO}_{\mathrm{sb}}\right), \mathrm{b}\right)$ forced expiratory volume in $1 \mathrm{~s}$ (FEV1), c) forced vital capacity (FVC) and $\mathrm{d}$ ) induced sputum neutrophil count. $\mathrm{p}<0.01$ (Spearman correlation). 


\section{TABLE 6 Correlation between induced sputum neutrophils and particles $<5 \mu \mathrm{m}$ and $<10 \mu \mathrm{m}$}

Neutrophils \% mean \pm sD

\begin{tabular}{|c|c|}
\hline \multicolumn{2}{|c|}{ Particles $<5 \mu \mathrm{m}^{\#}$} \\
\hline$\geqslant 91.93 \%$ & $64.4 \pm 24.9(n=48)$ \\
\hline$<91.93 \%$ & $52.4 \pm 21.1(n=45)$ \\
\hline \multicolumn{2}{|c|}{ Particles $<10 \mu m^{\pi}$} \\
\hline$\geqslant 95.17 \%$ & $65.7 \pm 25.2(n=64)$ \\
\hline$<95.17 \%$ & $55.5 \pm 22.6(n=29)$ \\
\hline
\end{tabular}

collapse [10]. The utility of neutrophil counts in induced sputum samples was demonstrated in other pulmonary disorders as well. For example, sputum neutrophil counts were associated with more severe asthma phenotypes using cluster analysis [23]. Additionally, eosinophilic and neutrophilic counts in induced sputum samples could differentiate between asthma, COPD and asthma-COPD overlap syndrome [24].

The ability of particles to penetrate the respiratory system may be one of several factors relevant to the development of silicosis. Although many studies have found associations between ambient particulate matter concentrations and health effects in occupational exposure to crystalline silica [7, 13], none estimated the internal personal-level burden by means of biological monitoring. We now demonstrated that most of the particles in the airways showed a distribution pattern similar to that of the raw artificial stone material, and that there was a significantly higher fraction of small particles $<5 \mu \mathrm{m}$ and a lower fraction of particles between 5 and $10 \mu \mathrm{m}$ in the exposed group compared to the nonexposed control group. It is well known that penetration of inhaled particles into the thorax is dependent on their deposition in the upper respiratory tract during inspiration, which varies with particle size, flow rate and tidal volume, as well as in vivo airway dimensions [25]. The fraction of small particles was shown to be a more dangerous one, with intratracheal instillation of ultrafine particles leading to a significantly greater pulmonary inflammatory response than larger-sized particles [26]. Fine particles that penetrate into the interstitium will make contact with interstitial macrophages and other sensitive cell populations, and this is likely to have a powerful inflammogenic effect that underlies the development of subsequent disease [27].

Furthermore, we found that the shape of the particle in the airways of exposed workers was significantly different compared to the nonexposed controls. In a recent review dealing with the potential biological effects of very small particles, the authors highly recommended that the shape, crystal phase, dispersion, surface coating and chemical composition should also be well characterised [28]. Our data indicated that a cut-off at $91.93 \%$ of particles $<5 \mu \mathrm{m}$ in size is associated with the risk of having neutrophilic inflammation (neutrophils $>65 \%$ ) and $D \mathrm{LCO}_{\mathrm{sb}}$ impairment $(<80 \%)$. The association between particle size, decreasing $D \mathrm{LCO}_{\mathrm{sb}}$ and high neutrophil counts may reflect the highly sensitive ability of these novel biomarker parameters to show early pathological changes in the lung in these exposed workers.

We had earlier reported that the use of masks and hoods and the type of exposure yielded differences in the shape of induced sputum particles of dental technicians working with any kind of protection compared to those without protection [12]. We show here that unprotected workers had an increased risk of having more particles $<5 \mu \mathrm{m}$ and $<10 \mu \mathrm{m}$ in induced sputum samples, neutrophilic inflammation and $D \mathrm{LCO}_{\mathrm{sb}}$ impairment compared to the group who regularly used personal protection. Direct impairments of PFT have been shown to correlated with efficient use of personal protection equipment in iron foundry

TABLE 7 Odds ratios for associations between the use of personal dust protection and neutrophil accumulation and single-breath diffusing capacity of the lung for carbon monoxide $\left(D\left\llcorner\mathrm{CO}_{\mathrm{sb}}\right)\right.$ decline

\begin{tabular}{|c|c|c|}
\hline & OR $(95 \% \mathrm{CI})$ & p-value ${ }^{\#}$ \\
\hline Particles $<5 \mu \mathrm{m}>91.93 \%$ & $7.0(1.3-36.2)$ & 0.017 \\
\hline Particles $<10 \mu \mathrm{m}>95.17 \%$ & $7.8(2.4-25.5)$ & 0.001 \\
\hline Neutrophils $>65 \%$ & $1.382(0.4-4.2)$ & 0.777 \\
\hline$D \mathrm{LCO}_{\mathrm{sb}}<80 \%$ pred & $1.471(0.5-4.0)$ & 0.613 \\
\hline
\end{tabular}



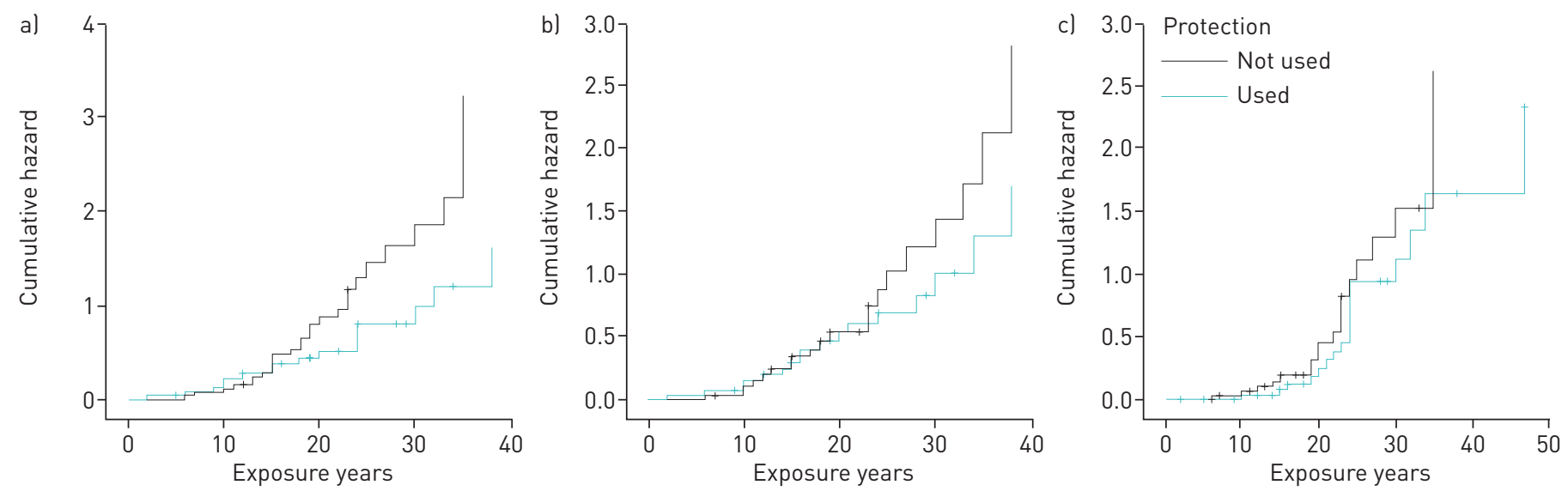

FIGURE 3 Hazard ratio for a) accumulation of particulate matter (particles $<5 \mu \mathrm{m}$ ), b) neutrophilic inflammation, and c) decreased single-breath diffusing capacity of the lung for carbon monoxide following years of exposure according to the use of personal protective measures.

workers [29] and in agate grinding workers exposed to silica [30]. To the best of our knowledge, this is the first study to document a direct effect of personal protection on internal exposure metrics in correlation to inflammatory parameters.

Our examination of the composition of the artificial stone material yielded interesting findings. Although it does contain mainly silica, we found that metals such as zirconium, titanium and aluminium were present in significantly higher percentages than their content in natural stone. Those metals are well known to induce sarcoid-like granulomatosis [31]. Importantly, the pattern of a high content of silica and metals contained in the material was reflected in the content of these metals in the induced sputum samples. This also goes along with the reported radiological presentation of many of the artificial dust-induced silicosis cases that mimic sarcoidosis [32].

This report also describes the first application of XRF technology for quantitating elements in biological samples. Previously used methods, such as scanning electron microscopy, only detect the chemical elements qualitatively [33].

There are some limitations to this study that need to be addressed. Our study population was relatively small, but they were all exposed to the same dust and so we believe that they are representative of workers in comparable workplaces. Another limitation was the lack of data on environmental monitoring, since these small enterprises are not regularly monitored; instead, we examined the settled dust, which turned out to have the same composition as the airborne particles. Another practical limitation is that sputum induction is a labour-intensive technique mainly performed in specialised centres by trained technicians. It is, however, a relatively inexpensive and noninvasive method that can be applied in high-risk, exposed populations.

We can conclude, however, that the novel functional and inflammatory biomarkers in induced sputum samples can effectively detect and monitor lung injury associated with artificial dust-induced silicosis. Finally, although the implementation of protective measures is highly recommended, they may only slow down the development of disease.

\section{Acknowledgements}

This work was performed in partial fulfilment of the requirements for a $\mathrm{PhD}$ degree by Noa Ophir.

\section{References}

$1 \quad$ Kramer MR, Blanc PD, Fireman E, et al. Artificial stone silicosis. Chest 2012; 142: 419-424.

2 Perez-Alonso A, Cordoba-Dona JA, Millares-Lorenzo JL, et al. Outbreak of silicosis in Spanish quartz conglomerate workers. Int J Occup Environ Health 2014; 20: 26-32.

3 Pascual S, Urrutia I, Ballaz A, et al. Prevalence of silicosis in a marble factory after exposure to quartz conglomerates. Arch Bronconeumol 2011; 47: 50-51.

4 Bartoli D, Banchi B, Di Benedetto F, et al. Silicosi negli addetti alla lavorazione di piani da cucina, banconi di bar e negozi, ecc. in agglomerato quarzo resina. Risultati provvisori dell'indagine ambientale e sanitaria condotta nel territorio della USL 11 di Empoli (FI) in Toscana, tra gli addetti alla lavorazione di materiali in agglomerato quarzo-resina e revision della letteratura sull'argomento. [Silicosis in employees in the processing of kitchen, bar and shop countertops made from quartz resin composite. Provisional results of the environmental and health survey conducted within the territory of USL11 of Empoli in Tuscany among employees in the processing of quartz resin composite materials and review of the literature.] Ital J Occup Environ Hyg 2012; 3: 138. 
5 Friedman GK, Harrison R, Bojes H, et al. Notes from the field: silicosis in a countertop fabricator - Texas, 2014 MMWR Morb Mortal Wkly Rep 2015; 64: 129-130.

6 Frankel A, Blake L, Yates D. Complicated silicosis in an Australian worker from cutting engineered stone countertops: an embarrassing first for Australia. Eur Respir J 2015; 46: Suppl. 59, PA1144.

7 US Department of Labor Office of Public Affairs. US Department of Labor's OSHA cites Cherry Hill, NJ, company for worker exposure to silica, other health and safety hazards. www.osha.gov/pls/oshaweb/owadisp.show_ document?p_table=NEWS_RELEASES\&p_id=19161. Date last accessed: April 10, 2012. Date last updated: January 26, 2011.

8 Jayaram L, Pizzichini MM, Cook RJ, et al. Determining asthma treatment by monitoring sputum cell counts: effect on exacerbations. Eur Respir J 2006; 27: 483-494.

9 Fireman E, Lerman Y, Stark M, et al. Detection of occult lung impairment in welders by induced sputum particles and breath oxidation. Am J Indust Med 2008; 51: 503-511.

10 Fireman EM, Lerman Y, Ganor E, et al. Induced sputum assessment in New York City firefighters exposed to World Trade Center dust. Environ Health Perspect 2004; 112: 1564-1569.

11 Lerman Y, Segal B, Rochvarger M, et al. Induced-sputum particle size distribution and pulmonary function in foundry workers. Arch Environ Health 2003; 58: 565-571.

12 Stark M, Lerman Y, Kapel A, et al. Biological exposure metrics of beryllium-exposed dental technicians. Arch Environ Occup Health 2014; 69: 89-99.

13 Occupational Exposure to Respirable Crystalline Silica - Review of Health Effects Literature and Preliminary Quantitative Risk Assessment Occupational Safety and Health Administration Docket OSHA20100034. https:// www.osha.gov/silica

14 Gamble JF, Hessel PA, Nicolich M. Relationship between silicosis and lung function. Scand J Work Environ Health 2004; 30: 5-20.

15 Miller MR, Hankinson J, Brusasco V, et al. Standardisation of spirometry. Eur Respir J 2005; 26: 319-338.

16 Pin I, Gibson PG, Kolendowicz R, et al. Use of induced sputum cell counts to investigate airway inflammation in asthma. Thorax 1992; 47: 25-29.

17 Popov T, Gottschalk R, Kolendowicz R, et al. The evaluation of a cell dispersion method of sputum examination Clin Exper Allergy 1994; 24: 778-783.

18 Fireman E, Greif J, Schwarz Y, et al. Assessment of hazardous dust exposure by BAL and induced sputum. Chest 1999; 115: 1720-1728.

19 National Insurance Institute of Israel. Work Injury - Information Centers for Occupational Safety and Hygiene. www.btl.gov.il/English\%20Homepage/Benefits/Work\%20Injury\%20Insurance/Pages/InformationCenters.aspx

20 Antao VC, Pinheiro GA, Terra-Filho M, et al. High-resolution CT in silicosis: correlation with radiographic findings and functional impairment. J Comp Assist Tomogr 2005; 29: 350-356.

21 Choudat D, Triem S, Weill B, et al. Respiratory symptoms, lung function, and pneumoconiosis among self employed dental technicians. Br J Indust Med 1993; 50: 443-449.

22 Antao VCD, Pinheiro GA, Kavakama J, et al. High prevalence of silicosis among stone carvers in Brazil. Am J Indust Med 2004; 45: 194-201.

23 Moore WC, Hastie AT, Li X, et al. Sputum neutrophil counts are associated with more severe asthma phenotypes using cluster analysis. J Allergy Clin Immunol 2014; 133: 1557-1563.

24 Global Initiative for Asthma, Global Initiative for Chronic Obstructive Lung Disease. Diagnosis of Diseases of Chronic Airflow Limitation: Asthma, COPD and Asthma-COPD Overlap Syndrome (ACOS). www.goldcopd.org/ uploads/users/files/AsthmaCOPDOverlap.pdf Date last updated: 2014.

25 Thurston G, Lippmann M. Ambient particulate matter air pollution and cardiopulmonary diseases. Semin Respir Crit Care Med 2015; 36: 422-432.

26 Oberdorster G, Ferin J, Lehnert BE. Correlation between particle size, in vivo particle persistence, and lung injury. Environ Health Perspect 1994; 102: 173-179.

27 Donaldson K, Li XY, MacNee W. Ultrafine (nanometre) particle mediated lung injury. J Aerosol Sci 1998; 29 553-560.

28 Wang J, Fan Y. Lung injury induced by $\mathrm{TiO}_{2}$ nanoparticles depends on their structural features: size, shape, crystal phases, and surface coating. Int J Mol Sci 2014; 15: 22258-22278.

29 Gomes J, Lloyd OL, Norman NJ, et al. Dust exposure and impairment of lung function at a small iron foundry in a rapidly developing country. Occup Environ Med 2001; 58: 656-662.

30 Rafeemanesh E, Majdi MR, Ehteshamfar SM, et al. Respiratory diseases in agate grinding workers in Iran. Int J Occup Environ Med 2014; 5: 130-136.

31 Newman LS. Metals that cause sarcoidosis. Semin Respir Infect 1998; 13: 212-220.

32 Shtraichman O, Blanc PD, Ollech JE, et al. Outbreak of autoimmune disease in silicosis linked to artifical stone. Occup Med 2015; 65: 444-450.

33 Fireman EM, Lerman Y, Ben Mahor M, et al. Redefining idiopathic interstitial lung disease into occupational lung diseases by analysis of chemical composition of inhaled dust particles in induced sputum and/or lung biopsy specimens. Toxicol Ind Health 2007; 23: 607-615. 